\title{
Applications of bacterial-synthesized cellulose in veterinary medicine - a review
}

\author{
Ioana Maria Bodea ${ }^{1}$, Giorgiana Mihaela Cătunescu², Teodor Florian Stroe ${ }^{1}$, \\ Sonia Alexandra Dîrlea ${ }^{1}$, Florin Ioan Beteg ${ }^{1}$
}

\author{
${ }^{1}$ University of Agricultural Sciences and Veterinary Medicine Cluj-Napoca, \\ Faculty of Veterinary Medicine, Cluj-Napoca, Romania \\ ${ }^{2}$ University of Agricultural Sciences and Veterinary Medicine Cluj-Napoca, \\ Faculty of Agriculture, Cluj-Napoca, Romania
}

Received November 13, 2018

Accepted October 29, 2019

\begin{abstract}
Tissue engineering promotes tissue regeneration through biomaterials that have excellent properties and have the potential to replace tissues. Many studies show that bacterial cellulose (BC) might ensure tissue regeneration and substitution, being used for the bioengineering of hard, cartilaginous and soft tissues. Bacterial cellulose is extensively used as wound dressing material and results show that BC is a promising tissue scaffold (bone, cardiovascular, urinary tissue). It can be combined with polymeric and non-polymeric compounds to acquire antimicrobial, cell-adhesion and proliferation properties. To ensure proper tissue regeneration, the material has to be: biocompatible, with minimum tissue reaction and biodegradability; bio-absorbable, to promote tissue development, cellular interaction and grow; resistant to support the weight of the newly formed tissue. Its versatile structure, physical and biochemical properties can be adjusted by adapting the bacteria culturing conditions. The main biomedical applications seem to be as hard (bone, dental), fibrocartilaginous (meniscal) and soft tissue (skin, cardiovascular, urinary) substituents. This paper reviews the current state of knowledge, challenges and future applications of $\mathrm{BC}$ and its biomedical potential in veterinary medicine. It was focused on the main uses in regeneration and scaffold tissue replacement and, although BC showed promising results, there is a lack of successful results of $\mathrm{BC}$ use in clinical practice. Most studies were performed only at experimental level and further research is needed for BC to enter clinical veterinary practice.
\end{abstract}

Biocellulose, biomaterial, biotechnology, tissue engineering, animals

The demand for new scaffold materials is increasing, requiring active involvement in the process of tissue regeneration (Sulaeva et al. 2015). Tissue engineering is a versatile field that combines material engineering with cell biology and suitable biochemical factors for the development of an artificial scaffold able to maintain and aid in the regeneration damaged tissues (Amalraj et al. 2018). It is an advanced biotechnology that tackles the developing of biological substitutes to replace, repair or support normal tissue function (Rajwade et al. 2015). A perfect scaffold requires a material which is biocompatible, biodegradable and nontoxic to the cells, both in the original and degraded forms (Amalraj et al. 2018).

In veterinary medicine, studies report that bacterial cellulose (BC) was used in the bioengineering of hard (Saska et al. 2011; Yoshino et al. 2013), fibrocartilaginous (Tanaka et al. 2014) and soft tissue engineering (Bodin et al. 2010; Lima et al. 2017). Bacterial cellulose is a polysaccharide used as scaffold in various medical fields (Rajwade et al. 2015). It possesses a potential as both matrix and reinforcement material. It is an extensively used biomaterial due to its unique characteristics: biocompatibility, high purity, high crystallinity and exceptional mechanical properties (Hickey and Pelling 2019). Its unique 3D nanofibre structure is produced by several strains of Gram-negative bacteria, 
among them Gluconacetobacter xylinus (Petersen and Gatenholm 2011), which produce extremely hydrated membranes (up to $99 \%$ water). Bacterial cellulose producing bacteria can be managed using a diversity of techniques to produce nearly any shape or form of membrane. Fibre orientation and surface chemistry can also be successfully controlled (Petersen and Gatenholm 2011). It can be produced in various forms, thus the mechanical properties vary widely. Bacterial cellulose has an ultrafine three-dimensional network structure with different pore sizes, which permits the absorption of water or other substances such as: montmorillonite (MMT) (Ul-Islam et al. 2012), vaccarin (Qiu et al. 2016), glycerin (Almeida et al. 2014). Thus, increasing BC native porosity is one of the main objectives of the current research in scaffolding and cell growth (de Oliveira Barud et al. 2016).

Polymeric (alginate, chitosan, cellulose) and non-polymeric composites were developed to extend its antimicrobial (Wu et al. 2014), biocompatible (Angtika et al. 2018) and tissue regeneration properties (Mandour et al. 2019). Newly elaborated scaffolds used as tissue replacement are gaining the attention of biomedical research. Studies on biomaterials concluded that BC (Neto and Dolci 2010; Kim et al. 2013; Yoshino et al. 2013) or $\mathrm{BC}$ composites (Saska et al. 2011; Pigossi et al. 2015) could replace both hard (Saska et al. 2012; Yoshino et al. 2013; Suwandi et al. 2015) and soft tissues (Almeida et al. 2014; Scherner et al. 2014; Xu et al. 2014).

Thus, there are several known practical applications for BC in the medical domain, but there is a lack of pertinent presentation of their application in veterinary practice. Although $\mathrm{BC}$ was extensively tested on laboratory animals and is currently used in human medicine, its use in veterinary practice is scarce. Thus, the aim of this review was to summarize and critically present the main properties of $\mathrm{BC}$, advantages and drawbacks of its use in animal tissue engineering. We tried to provide a summary on the status of $\mathrm{BC}$ based membranes used in tissue engineering in veterinary medicine. It seems to show great promise in tissue bioengineering due to its diversity and versatility of biochemical and physical properties as a tissue engineering scaffold. However, further research and practical case studies are needed to fully disclose the clinical applications of BC membranes.

\section{Hard tissue engineering}

Bone and dental injuries are the main areas of concern in tissue engineering and regenerative medicine (Kargozar et al. 2019). A wide range of grafts and graft substitutes are available. Autograft, allograft, and xenograft are the most commonly used natural bone substitutions; however, autogenous bone remains the gold standard (Daugela et al. 2018). Their use is limited because they can cause donor site morbidity, increased postoperative pain, prolonged healing and, eventually, delayed revascularization (Zimmermann et al. 2011; Shi et al. 2012). In addition, the risk of immunogenic activation and disease transmission is high and xenografts have the potential to transmit zoonotic diseases and prion infection (Zimmermann et al. 2011; Daugela et al. 2018). Therefore, the interest is growing for new biomaterials that could potentially replace damaged bones and teeth (Kargozar et al. 2019).

Nowadays, a large number of synthetic implants (polymers, ceramics, and metals) and their composites provide numerous advantages (they are bioactive, with osteoconductive and osteoinductive properties) (Suwandi et al. 2015) compared to autografts in reconstruction of hard tissue defects (Ullah et al. 2016; Kargozar et al. 2019). Metals and ceramics are usually used as hip implants (Zimmermann et al. 2011), but they do not have optimal properties. They display deficient osseointegration and eventually fail because of infections or fatigue loading (Zaborowska et al. 2010; Daugela et al. 2018). In addition, there is a possibility of inducing granulomas and fibrous reactions at the implantation site. 
Methacrylic polymers and hydroxyapatite (HA) composite cements were proposed, but these biomaterials are not resorbable (Suwandi et al. 2015). Thus, new bone grafting materials are needed to help the body's own repair mechanism. They should display a network of interconnected pores to allow cell migration and nutrient transport to the cells (Zaborowska et al. 2010). Thus, porous interconnected 3D scaffolds (chitosan, alginate, bacterial cellulose) are a more attractive choice because they can fill cracks, gaps or other defects; they degrade rapidly and provide a structure for bone regeneration (Daugela et al. 2018). Natural bone is highly porous; therefore, highly porous materials for bone tissue engineering are needed. The porous mineralized scaffolds increase osteoblast attachment and cell density at the pore sites (Martínez Ávila et al. 2015). Natural bone consists mainly of collagen and minerals similar in composition to hydroxyapatite. Thus, the mimicking of this complex composition is essential for bone tissue engineering (Saska et al. 2011).

Natural polymers (chitosan, collagen, cellulose) offer several advantages, because of their biocompatibility, hydrophilicity and biodegradability (Daugela et al. 2018). Ideally, a tissue engineering scaffold degrades in the site of implantation at a rate corresponding with the rate of tissue regeneration and promotes non-toxic degradation products that are either metabolized or eliminated from the body (Roman et al. 2019). Generally, the in vivo degradation of biomaterials can occur through thermal, mechanical, chemical, or enzymatic processes (Roman et al. 2019).

To ensure bone regeneration, polymers should be biocompatible, biodegradable, easily sterilized, adequate biomimetic properties (water content, optimal mechanical properties and porosity). Also, it has to provide suitable bioactivity to promote cell attachment and proliferation on the scaffold (Daugela et al. 2018; Sajjad et al. 2019).

Bacterial cellulose mimics the extracellular matrix: the nanofibrillar structure is comparable to collagen. In medical applications, cellulose has no immunogenic reactivity, compared to collagen (de Oliveira Barud et al. 2016). It is non-toxic, it performs satisfactorily and induces a suitable host response upon specific application (Rajwade et al. 2015). The tensile strength of a single cellulose fibre is almost comparable to steel (Picheth et al. 2017), being a good choice for applications where high mechanical performance is needed (Rajw ade et al. 2015; Ullah et al. 2016). Bacterial cellulose and BC composites offer high mechanical strength matching with cancellous bone; improved biomineralization for bone growth (Martínez Ávila et al. 2015); good osteogenic properties (Pigossi et al. 2015); improved mechanical strength (Tanaka et al. 2014); increased cell viability and substantial cell growth (Gea et al. 2018); enhanced cell proliferation; non-toxic and good biocompatibility (Zang et al. 2014) and comparable compositional, structural and mechanical properties with trabecular bone (Amalraj et al. 2018).

Cellulose is a linear-chain polymer with several hydroxyl groups with a degree of crystallinity dependent on its source. Bacterial cellulose has relatively high thermal (An et al. 2017), mechanical (Tanaka et al. 2014), and chemical (Kwak et al. 2015) stability in the absence of cellulolytic enzymes, making BC resistant to biodegradation (Daugela et al. 2018). Cellulose degradation is achieved by cellulases, cellulose degrading enzymes, which do not exist in the mammalian body (An et al. 2017; Daugela et al. 2018).

Distinct polymorphs of cellulose are known, including cellulose I, II, III and IV. But, only amorphous cellulose (cellulose II) is completely biodegradable in bone defects, by acidic hydrolysis, which does not appear in the crystalline phase (Daugela et al. 2018). So, its biodegradability in vivo depends on its crystallinity (Daugela et al. 2018). Thus, the regenerated new tissue cannot replace the cellulose scaffold (Hickey and Pelling 2019). This resistance to biodegradability is generally considered the main limitation of $\mathrm{BC}$ for use in tissue engineering applications. Several methods were proposed to overcome this problem of crystalline cellulose such as acid hydrolysis, alkaline hydrolysis and 
pretreatment with ionic liquids. Still, these methods have limitations, such as difficulty in precisely controlling degradation and potential cytotoxicity of chemical residues in $\mathrm{BC}$ preventing clinical application (An et al. 2017).

There is an on-going dispute on the use of biodegradable materials compared to permanent constructs (Kargozar et al. 2019). Both have advantages and disadvantages. While both biodegradable and non-biodegradable materials fill the defects, the biodegradable structures provide a timely degradation process, allowing new tissue to take its place, while permanent constructs do not offer this advantage (Daugela et al. 2018). Although BC will occupy the space intended for the bone tissue, it can provide constant structural support (Hickey and Pelling 2019). On the contrary, the relative stability of BC confers ease of sterilization with heat, steam, ethylene oxide gas, or radiation; a long shelf life of the sterile material and prolonged structural integrity upon implantation (Roman et al. 2019). A biologically inert material is desired to eliminate foreign body responses (Oliveira Barud et al. 2015). Nevertheless, completely biologically inert materials do not exist.

Bioactivity is the ability of materials to promote attachment of cells and proliferation on the scaffold (Roman et al. 2019). Therefore, proper bioactivity is a key requirement to obtain certain responses (Hickey and Pelling 2019).

Cellulose nanofibres/hydroxyapatite composites were used to mimic natural bone. The main properties of the tested composites were Young's moduli greater than 15 GPa (Hickey and Pelling 2019); tensile straight ranges between 2.2 MPa (Tanaka et al. 2014) and $450 \mathrm{MPa}$; a crystallinity of about $17.63 \%$ (Kwak et al. 2015); 3D structure (Yang et al. 2012), porosity with larger average pore size that can range from 100 to $500 \mu \mathrm{m}$ (Wu et al. 2019) and biocompatibility (Ullah et al. 2016). Moreover, BC materials have good consistency and viscosity. The stimulating native bone tissue mineralization was also observed (Hickey and Pelling 2019).

The use of a $\mathrm{BC}$ hydroxyapatite (BC-HA) composite was tested in mice with critical-size bone defects in the left parietal bone (lateral ostectomy) with a 4-mm-diameter trephine bur (Pigossi et al. 2015). Bone defects in the control group were allowed to fill with only the blood clot. Bone defects of the other experimental groups received a membrane as follows: BC-HA (hydroxyapatite); BC-HA OGP (hydroxyapatite and osteogenic growth peptide); BC-HA OGP (10-14) (hydroxyapatite and osteogenic growth peptide proteolytically cleaved). The animals were euthanized $3,7,15,30,60$, and 90 days postoperatively. On day 3, all experimental groups revealed incipient granulation tissue, supported by thin collagenous fibres, fibroblasts and blood vessels, also, viable osteocytes on the edges of the critical-size defect. After 7 days, a moderate inflammatory reaction remained in the BC-HA and BC-HA OGP (10-14) groups, and a very slight reaction was seen in the BC-HA OGP membrane and in the control group. After 15 days, the granulation tissue was found to fill the defect, along with the presence of connective tissue that was more fibrous than that in previous periods. Similarly, 30 days postoperatively, the presence of fibrous connective tissue was observed on the edges of the defects with collagenous fibres in a regular pattern in all groups. Lastly, after 60 and 90 days, the periosteum covering the defect was noted, and the absence of inflammatory reactions was seen in all groups. Furthermore, after 60 and 90 days, in both treated and control groups, the critical-size bone defects were not fully regenerated and newly formed bone appeared in various stages of maturation. However, in the treatment groups, the membranes promoted greater bone formation than in the control group. Bacterial cellulose-HA membranes seemed efficient in bone regeneration in mice models, although the incorporated peptides did not improve bone reconstruction. Future studies should be performed to improve the effectiveness of the peptide release time at the required concentration for longer periods.

The efficacy of BC-HA composite was evaluated as well on rat tibia bone with a 2-mm size defect. In the treated group, the left tibia defects were filled with a blood clot and 
covered by the BC-HA membrane, in the control group the right tibia defects were filled with only a blood clot. Animals were evaluated at 1, 14 and 16 weeks (Saska et al. 2011). The BC-HA nanocomposite membrane showed newly formed bone and medullary spaces with mesenchymal cells within the defect site. However, in the control group, fibrotic tissue formation was observed within the defect site. Moderate inflammatory reaction could be observed for both groups at 4 weeks. After 16 weeks, the BC-HA membrane could still be observed, but, the bone defects were completely repaired by mature bone for both groups.

Bacterial cellulose scaffolds combined with biphasic calcium phosphate (BCP) ceramics were used in vivo as a local treatment to prevent fractures in osteopaenic bones (Suwandi et al. 2015). Osteoporosis is characterized by low bone mass and deterioration of microarchitecture of tissue leading to increased bone fragility and fracture risk (Nishiguchi and Taguchi 2019). A drastic and massive trabecular bone loss was induced in the femur of rats. The orchidectomized rats (ORX group) received a single injection of Clostridium botulinum neurotoxin in the quadriceps femoris of the right hind limb, while the control group was injected with saline (sham group). One month later, the external side of the right hind limb was incised and the quadriceps femoris was reclined to expose the lower third of the femur and a hole was drilled. Biphasic calcium phosphate was injected in the drilled hole to determine the potential restorative effect and bone loss. Micro CT revealed that in the treated group the drilled hole appeared filled by woven bone developed from the periosteum when evaluated 1, 2, and 3 months postoperatively. Marked bone formation was developed onto the biomaterial granules, but bone had a woven texture. Although the material temporarily improved, both the apposed woven bone and the $\mathrm{BCP}$ granules were resorbed without inducing lamellar bone tissue. The authors recommend the implantation of the biomaterials for more than 3 months in aged and osteoporotic animals for a permanent osseous microarchitecture restoration. Short-term periods seem to be insufficient to determine the remodelling of bone tissue. However, the use of BCP in young healthy animals should be avoided because they do not display the bone regeneration rate noticed in osteoporotic rats (Suwandi et al. 2015).

Thus, more experimental studies are needed. Although BC composites seem a promising choice in bone tissue regeneration, due to its mechanical and biological properties, there is a lack of conclusive results that could make it applicable in clinical practice. The results so far seem promising, but a material that meets all the properties of a bone scaffold still needs to be developed.

In dental implant and prosthetic dentistry, the sustaining of residual alveolar bone is crucial after tooth-loss to increase clinical success. However, it usually faces limitations due to factors such as infection (Yoshino et al. 2013), external injury (Sadiasa et al. 2013), and other lesions (Lee et al. 2015). Dental root canal treatment is needed and complete decontamination is required when dental cavities progress and infect the dental pulp (Sadiasa et al. 2013). The morphology of the root canal is complex and dental reinfection is common (Yoshino et al. 2013). Thus, proper drying and sterilization of the material used in dental disease is required. Such treatment requires a highly absorbent biocompatible material to improve the efficacy of intracanal medication (Yoshino et al. 2013). Bacterial cellulose seems to have all these qualities needed in dental canal treatment: biocompatibility (Zhu et al. 2014), high absorbance (Yoshino et al. 2013), good mechanical properties (Hickey and Pelling 2019), drug absorption and release capacity (Mohite et al. 2019).

Bacterial cellulose membrane was successfully applied in the treatment of class II furcation lesions - a type of periodontal disease - in dogs (Novaes et al. 1993). The third and fourth mandibular premolars were chosen for treatment. The animals were euthanized after 4 weeks, or after 8 weeks ( 4 weeks from removal of BC) for evaluation. Results revealed that the control group showed isolated connective tissue while new formation 
of cement was observed in the experimental group. The dogs treated with BC presented an increase in osteoblast cells and newly formed collagen fibres. Slight improvement was noticed in the control group, while complete bone regeneration was observed in the treated group.

Bacterial cellulose was implanted in the subcutaneous layer on the back, into the latissimus dorsi muscle, and under the periosteum of the mandibular angle in Sprague Dawley (SD) rats to evaluate its potential in dental canal treatment, compared to commercially available plant cellulose paper points (PP) (Yoshino et al. 2013). Specimens were explanted with the surrounding tissue. Bacterial cellulose was surrounded by mild inflammatory cells on day 3, while PP appeared fragmented and inflammatory cells infiltrated the spaces between the PP fragments. A higher number of giant cells were observed for PP than for BC 8 days later. The results showed that $\mathrm{BC}$ had better physical properties than $\mathrm{PP}-$ higher liquid absorption and expansion capacity. Bacterial cellulose showed similar results in the latissimus dorsi muscle.

Thus, BC can be used successfully in periosteal disorders due to its absorbent properties. It has higher absorption capacity, greater purity than commercially available plant PP, and it is ecological. In addition, the use of BC in the treatment of various dental diseases seems promising, but more studies are needed to confirm the current results.

Bacterial cellulose seems to show great promise for bone/dental regeneration due to its unique properties: adequate surface chemistry, biocompatibility, non-toxicity and controllable biodegradability. Biodegradable BC-based materials can be engineered for hard tissue application. Animal experiments showed that $\mathrm{BC}$ preserved bone physical integrity, it did not fragment and only a slight foreign body reaction was noticed. These results indicate a good potential in the use of $\mathrm{BC}$ as a biomaterial for hard tissue reconstruction. However, its osteogenic, osteoinductive and osteoconductive properties depend on the chemical composition of the used composite material (Daugela et al. 2018; Kargozar et al.2019). In addition, a the balance between biodegradability and other scaffold properties (mechanical, chemical and structural) need to be optimized for individual applications (Roman et al. 2019).

\section{Fibrocartilaginous tissue engineering}

The cartilage is an avascular tissue constituted of only one type of cells - chondrocytes implanted in a collagen matrix (Milcovich et al. 2017), with limited self-repairing. Thus, repairing cartilage defects is a major clinical endeavor (Rajwade et al. 2015; de Oliveira Barud et al. 2016). Scaffolds should ensure cell production and proliferation. They need to support the differential functions of cells to help the complete development of the newly grown tissue. The main step in cartilage tissue engineering is choosing a suitable scaffold for cells growing to the desired function and shape (Gea et al. 2018).

The reconstruction of cartilage is usually difficult because of self-repair deficiency. Autogenous costal cartilage grafts are used in auricular cartilage reconstruction (Feldmann et al. 2013), however they have some disadvantages: multiple surgical interventions are needed and they do not satisfy the elastic properties of the auricle (Martinez Avila et al. 2014). In addition, complications might appear such as inflammation, erosion and extrusion (Feldmann et al. 2013). In joint disorders, total and partial meniscectomy may induce degenerative changes in the affected joint. These lesions often progress and lead to osteoarthritis (Guo et al. 2015).

Cartilage substitutes have to be non-biodegradable, resistant, biocompatible, non-cytotoxic (Petersen and Gatenholm 2011). Pore size has to be adequate for cell adhesion, proliferation, migration, differentiation and nutrient diffusion (Rajwade et al. 2015). Different pore sizes are required for cell migration and neovascularization 
(Roman et al. 2019). The water content of the extracellular matrix ranges from $60 \%$ in fibrous tissues, like tendons, to about $80 \%$ in healthy articular cartilage. The implant has to be structurally similar to the cellular tissue; it needs a high pore volume (typically above $0.90-0.95$ ) and an average pore diameter of 5 to $500 \mu \mathrm{m}$ (Gea et al. 2018). Additionally, the graft has to supply controllable degradation and absorption rate and to provide suitable elasticity (Rajwade et al. 2015).

The porosity of the material needs, however, to ensure the mechanical properties of the engineered tissue and $\mathrm{BC}$ could meet these requirements (de Oliveira Barud et al. 2016). Bacterial cellulose has the advantages of high tensile strength and good compatibility, making it a promising scaffold for fibrocartilaginous tissue as a collagen-mimicking scaffold (Gea et al. 2018). Bacterial cellulose membranes have a 3D network structure with 30-100 nm fibre diameter (Yang et al. 2012) and 120-160 nm pore size (Shahmohammadi Jebel and Almasi 2016). The architecture of BC can be engineered to vary from nano to macro structure (Yang et al. 2012). The porous structure has excellent interconnectivity and leads to a nanostructure and morphology very similar to collagen, being an attractive alternative to support and immobilize cells (Mohite et al. 2019). Bacterial cellulose can be obtained with a high purity (Petersen and Gatenholm 2011; Zhu et al. 2014), mechanical strength (Zhu et al. 2014; Tanaka et al. 2014), crystallinity (Daugela et al. 2018; Hickey and Pelling 2019), and microporosity (Yang et al. 2012; Lee et al. 2015). Bacterial cellulose can absorb up to $350 \%$ its own weight in water, depending on synthesis conditions (Kwak et al. 2015; Roman et al. 2019).

This encouraged the testing of $\mathrm{BC}$ in cartilage regeneration by various authors both in vitro and in vivo. Several in vitro studies tested BC scaffolds seeded with both human auricular and nasoseptal chondrocytes (Feldmann et al. 2013). Bacterial cellulose displayed good cell adhesion; proliferation; and, mostly promoted the maintenance of chondrogenic phenotype by synthesis of cartilage-specific extracellular matrix (Martinez Avila et al. 2014). These encouraging results led to further exploration on the potential use of BC as a nonresorbable scaffold material (Tanaka et al. 2014) for cartilage tissue engineering (Martinez Avila et al. 2014).

Bacterial cellulose scaffolds were tested in vitro for their ability to ensure the viability of chondrocytes, the main cellular components of cartilage (Gea et al. 2018). The cells were seeded on BC in monolayer for 9 days and the number of viable cells was counted. The chondrocytes were found to be viable after 9 days, and the number of cells was growing daily. A number of dead cells was, however, also evident. The results indicated that BC could be a potential alternative to synthetic polymer foam, such as polyglycolic acid, polylactic acid, polyvinyl alcohol in cartilage tissue engineering.

Bacterial cellulose was tested as a biosynthetic membrane after trochleoplasty to evaluate if it could support chondrogenic cell migration and tissue recovery (Iamaguti et al. 2008). The study was performed on both pelvic limbs of dogs to evaluate the improving of the osteochondral injury; the locomotion function of the legs; macroscopic and microscopic structure of the joint. Results showed a normal performance of the limbs; radiography revealed no difference from control groups and histologic exams evidenced immature chondrocytes and a more organized connective tissue of the implant. Finally, a mature fibrocartilaginous-like tissue was formed in both cellulose and control groups after 90 days postoperatively. The study concluded that the cellulose implant reduced the time needed for tissue healing in the trocleoplasty area and showed good incorporation of the neoformed tissue with the adjacent cartilage.

Similar positive results were found in an experiment on rabbits treated for nasal septum perforation with $\mathrm{BC}$ membrane by evaluating fibrosis, inflammation, vascular congestion and graft integrity (Neto and Dolci 2010). Septal perforation was performed on all animals and then divided in 3 groups: control; treated with cellulose Bionext ${ }^{\circledR}$ and fibrin glue 
Tissucol ${ }^{\circledR}$. No closure of the nasal septum defect was observed in the control group. The $\mathrm{BC}$ biomaterial showed superior biocompatibility and could be used for reepithelization of the perforation area because no acute inflammation, vascular congestion or fibrosis was present and the implant remained at the implantation site.

In contrast to these studies, cellulose biosynthetic membrane (CBM) was evaluated as coating in osteochondral defects in the femoral trochlear sulcus of dogs (Iamaguti et al. 2013). The defects were performed in both limbs and CBM was applied on the surface of all lesions. The treated group received CBM cultivated with homologous chondrocytes, while the control received no cellular implant. Although the treated group displayed increased density and viability rate, no significant differences were observed on histomorphometry of fibrous and fibrocartilaginous tissues. Newly formed tissue showed slightly higher quality in the treated group, but without advanced repair by hyaline cartilage.

In vivo evaluation of $\mathrm{BC}$ scaffolds was assessed on Wistar rats, randomly divided into 4 groups: control (no treatment); BC; bilayer scaffold (BC-HA and BC-GAG placed one over the other); and bilayer scaffold supplemented with growth factors (GF) (recombinant human BMP-2) (Kumbhar et al. 2017). Osteochondral defects (OCD) were created in the patellar groove of the knee joints and 6 animals from each group were sacrificed at 1 and 3 months. After surgery, no group showed any signs of infection or immunological rejection. One month post operation the control defect group showed defect margins covered with a semi-transparent white sparse fibrous tissue. The defect was visible and contained sparse fibrous tissue or fibrocartilage. The implanted BC scaffolds were visible, the edges of the defects could be clearly seen and were covered with incomplete neo-tissue. The bilayer and the bilayer + GF groups showed good surface regularity and an absence of visible cracks or fissures, often noticed in OCD repaired with polymers. Firm cartilage-like tissue filled the defect completely, which appeared similar in color and texture to the surrounding articular surface. Hyaline-like cartilage was observed on the edges or interior of the defect in the animals receiving the bilayer scaffold. In addition, signs of scaffold resorption and formation of neocartilage and bone was observed in the bilayer + GF group.

At 3 months, all control explants showed fibrous tissue in the defects without cartilagelike tissue regeneration. In the native BC group, the defect surfaces were slightly depressed but were covered with neo-tissue better than at 1 month. A mixture of fibrocartilage and cartilage-like tissues seemed to fill the defect and small bony islands in the scaffold were visible. Both the bilayer and the bilayer + GF scaffold group exhibited complete neocartilage and neobone formation at the defect site. Furthermore, full integration of the neo-tissue was noted in the surrounding healthy tissue. The bilayer group showed the presence of a small scaffold portion, yet the scaffold had completely resorbed in the bilayer + GF group (Kumbhar et al. 2017).

These results are promising and highlight the cellulose properties of cell attachment and proliferation having collagen matrix-like properties. But the in vivo results are not reliable enough. Although some studies showed promising results, composites have to be found to provide a higher success rate in regenerating cartilage. Bacterial cellulose based scaffolds need to be explored. Further extensive and long term evaluation of $\mathrm{BC}$ composites in other species is needed.

In addition, several studies concluded that $\mathrm{BC}$ could be a suitable material in meniscal tissue regeneration (Tanaka et al. 2014; Ullah et al. 2016). The meniscus is a semicircle fibrocartilaginous structure important in the normal knee movement (Tanaka et al. 2014). It is very susceptible to degeneration due to its location, traumatic injury or to forces that occur during movement (Ullah et al. 2016). The complete removal of meniscus was considered as a therapeutic option, until recently, but it leads to osteoarthritis; thus, the current treatment involves its replacement with materials that mimic its main characteristics (Tanaka et al. 2014). 
The mechanical properties of $\mathrm{BC}$ and meniscus from pig, sheep and human were compared (Tanaka et al. 2014). Bacterial cellulose had similar elastic properties to native meniscus, but exceeded the minimum demands for mechanical stress and strain. These results were quite encouraging, $\mathrm{BC}$ could be shaped as a meniscus and being a low-cost material makes it an attractive choice. However, further studies are needed, and mechanical properties should be improved to be as close as possible to those of meniscus.

Glottic incompetence is often a cause of paralysis, atrophy or loss of tissue. Surgical treatment is usually recommended: laryngectomy, substances introduction or injection lateral to the thyroarytenoid muscle, and material implantation. De Souza et al. (2011) tested tissue response and healing of vocal cords implanted with $\mathrm{BC}$ in a rabbit model. No notable inflammation was observed compared to control groups. Bacterial cellulose treated rabbits presented a medial displacement of vocal cords and the implants remained at the implantation site. There were no signs of rejection or absorption at the implantation site. Although these results seem encouraging, to the best of our knowledge, BC has not yet been clinically studied in laryngeal disease treatment. Thus, further clinical trials in this direction would be an important addition.

In conclusion, although $\mathrm{BC}$ has similar properties to cartilage: fibrous structure porosity, mechanical resistance and a good support for cell proliferation, the results so far are not conclusive for the application of this material in current practice. More in vivo studies are needed to prove the in vitro results. Although modest progress was made regarding the goal of a clinically useful cartilage regeneration material, further research should be aimed at strategies for rebuilding the native cartilage tissue.

\section{Soft tissue engineering}

Recent studies have investigated the use of $\mathrm{BC}$ for the regeneration of cardiovascular (Mohammadi 2011; Weber et al. 2018), nervous (Kowalska-Ludwicka et al. 2013; Zhu et al. 2014), urinary tissue (Huang et al. 2015; Lv et al. 2015). Bacterial cellulose was tested as wound dressing material (Mohamad et al. 2014; Qiu et al. 2016); artificial skin (Kwak et al. 2015); artificial blood vessels (Scherner et al. 2014); other biomedical devices because of its specific properties such as: the 3D nanomeric structures; unique physical, mechanical, and thermal properties; and its higher purity (Mohite et al. 2019). Bacterial cellulose also exhibits other attractive characteristics for soft tissue engineering, such as: a high degree of crystallinity ( $\mathrm{Zhu}$ et al. 2014); a high degree of polymerization and a high specific surface area $\left(37 \mathrm{~m}^{2} / \mathrm{g}\right)$ (Mohite et al. 2019). Furthermore, BC also offers a large surface area, high aspect ratio, and low bulk density, as well as hydrophilicity (Mohite et al. 2019). Different production protocols were evaluated to create different pore sizes (Shahmohammadi Jebel and Almasi 2016; Gea et al. 2018); different cultivation condition and time (Huang et al. 2013); also post-treatment of the cellulose (freeze-dried, gel-like membrane) to reach the desirable structure for soft tissue replacement (Mohite et al. 2019).

Damaged skin needs to be covered immediately with a dressing; otherwise it could lead to a prolonged healing time (Amalraj et al. 2018). Thus, it is essential to use a proper wound dressing to prevent additional damage and to promote healing ( $\mathrm{Kw}$ a k et al. 2015). Wound healing and skin regeneration need materials to provide proper moisture and actively participate in tissue regeneration. Thus, wound dressings should lead to efficient skin recovery (Ullah et al. 2016).

Bacterial cellulose has been used as wound dressing since 1980s (Rajwade et al. 2015) because of its biocompatibility, non-toxicity, and unique network structure. Bacterial cellulose promotes autolytic debridement; reduces pain (Qiu et al. 2016) and accelerates granulation (Petersen and Gatenholm 2011). It also matches different wound shapes and 
maintains proper water balance by either absorbing exudates or releasing fluid (Petersen and Gatenholm 2011; Sulaeva et al. 2015). Bacterial cellulose can incorporate drugs and optimally release them hastening healing (Yoshino et al. 2013). This integrates some advantages to the drug dosage, including diminution in dose frequency, decrease fluctuation in drug plasma concentration and improved patient comfort and therapeutic efficacy (U1lah et al. 2016).

Although $\mathrm{BC}$ has unique properties, there is a restriction in its applications as wound dressing such as: absence of antibacterial properties (Yang et al. 2012), optical transparency (Coelho et al. 2019), and stress bearing capability (Rajwade et al. 2015), properties needed in soft tissue engineering. To overcome these limitations, $\mathrm{BC}$ composites were developed (Mohamad et al. 2014; Qiu et al. 2016), which consist of a matrix and reinforcement materials. As BC has a porous structure and fibre arrangement, it acts as a support for a variety of reinforcements. The attached particles provide additional properties (antibacterial, transparency, resistance) to $\mathrm{BC}$ that enhance its natural biological and physiochemical properties (Yang et al. 2012; Sepúlveda et al. 2016).

Bacterial cellulose/acrylic acid (BC/AA) hydrogels were analysed on SD rats as treatment for burn wounds (Mohamad et al. 2014). The rats were divided into 3 groups: one treated with BC/AA, one with Intrasite Conformable ${ }^{\circledR}$ hydrogel (positive control group) and the third group received no treatment (negative control). The hydrogel appeared to be biocompatible, because in the BC/AA group no skin erythema, oedema or irritation was noticed. Significant macroscopic differences of wound closure were observed between the hydrogel and the control groups. The burn sites appeared red and swollen; no signs of infections or a decrease in size were detected initially. However, the negative control groups showed haemorrhagic, scabbed wounds in contrast to the BC/AA. Differences in wound closure were observed: the hydrogel and the positive control groups were almost completely healed compared to the untreated group. The rate of wound healing determined histologically was higher in BC/AA and positive controls. The physical and mechanical properties (exudate absorption and retention, tensile strength) of $\mathrm{BC} / \mathrm{AA}$ made it more suitable for skin burns because it accelerated healing and supported epithelialization.

Bacterial cellulose and vacarine-BC (BC-Vac) membranes were compared with petrolatum gauze and nanosilver dressing in a study performed on Institute of Cancer Research male mice (Qiu et al. 2016). Better fluid retention was observed in wounds treated with BC and BC-Vac; the membranes could be removed easily, without interfering with the healing process. Gauze dressings adhered to the wound and induced trauma on removal. Histologic examination showed little difference among groups, necrotic tissue and a larger number of inflammatory cells were determined in the commercial dressings group. Bacterial cellulose and $\mathrm{BC}$-Vac groups presented new vascularization, fewer inflammatory cells, dense newborn subcutaneous tissue, new granulation tissue, and collagen fibres. Thus, the results showed the effectiveness of $\mathrm{BC}$ and $\mathrm{BC}$-Vac membranes, as they displayed superior and faster wound healing, with BC-Vac membranes being the better of the two.

Skin regeneration and angiogenesis was evaluated on SD rats by treating induced burn skin wounds with BC membranes and with gauze (Kwak et al. 2015). The skin severity score was lower in the $\mathrm{BC}$ group, while epidermis, dermis thickness and angiogenesis were higher. Higher levels of collagen were observed on the $5^{\text {th }}$ day compared to the gauze group, and lower ones on the $10^{\text {th }}$ and $15^{\text {th }}$ days. In conclusion, $\mathrm{BC}$ treatment of burn wounds accelerated the healing by promoting angiogenesis and connective tissue formation.

Further research on the use of $\mathrm{BC}$ and $\mathrm{BC}$ composites in skin tissue engineering is required to extend its healing ability on several types of skin lesions. Their drug carrier properties and controlled release of drugs need to be explored and exploited for new dressing development. Nowadays, gauze is a major clinical wound dressing, but BC wound based dressings seem to be a promising alternative. Recent studies indicate biocompatibility and 
histocompatibility of $\mathrm{BC}$, significant tissue regeneration and faster healing. These results are promising, highlighting the clinical potential of $\mathrm{BC}$ in the future in skin tissue repair.

Blood vessels serve blood circulation in normal condition. But in some cases, they can be damaged due to pathological conditions and require replacement with artificial blood vessels (Scherner et al. 2014). The discrepancy between the properties of the vascular graft, the nearby native tissue and the ultimate graft failure has to be considered in cardiovascular diseases (U1lah et al. 2016). The most commonly used vascular grafts are expanded polytetra-fluoroethylene (ePTFE) and polyethylene terephthalate (PET) (Malm et al. 2012). Despite the high success rate of these materials, their use in small vessels is limited due to thrombosis (Malm et al. 2012). There is a need for other haemocompatible materials with appropriate biochemical and physical properties for vasculature engineering (Hickey and Pelling 2019).

Bacterial cellulose can be used as a synthetic graft, due to its great properties and biocompatibility (U1lah et al. 2016). Several studies evaluated BC in comparison with commercial available grafts (Millon and Wan 2006; Mohammadi 2011).

The mechanical strength of the tubes is essential, as they have to resist during anastomosis and normal blood pressure. Artificial BC implants were tested before use for resistance to high blood pressure by suture retention and bursting strength. The results showed that they could be implanted with no complications (Scherner et al. 2014). Bacterial cellulose tubes were compared with several animal blood vessels (sheep, pig) and the results showed that they were proper for the microsurgery of artificial blood vessels.

Klemm et al. (2001) described a new biomaterial - BASYC ${ }^{\circledR}$ - designed for artificial blood vessel microsurgery. Microtubes had a regular form but varying lengths, diameters, and thicknesses. Similar tubes were obtained by Wippermann et al. (2009). Klemm et al. (2001) implanted BC BASYC ${ }^{\circledR}$ tube in Wistar rats. Bacterial cellulose tubes were covered with surrounding tissue and penetrated with new small vessels, thus, being entirely incorporated with no adverse reaction from the body. Histological examination showed that the BASYC ${ }^{\circledR}$ tube-artery complex was covered with connective tissue and the inner surface presented well-organized endogenous cells. The vascular wall proved the vivification of the implant. The tube showed no sign of alteration compared to the control contralateral carotid artery.

Scherner et al. (2014) tested the compatibility of vascular grafts on sheep and Wippermann et al. (2009) on juvenile, white domestic pigs, by suturing a BC implant instead of a resected carotid portion. Macroscopic and histological examination showed no signs of inflammation around the $\mathrm{BC}$ grafts or at the suture site. A modest foreign tissue reaction was, however, observed: a fibrotic tissue around the graft. Specific histological staining revealed that the matrix of $\mathrm{BC}$ provided proper support for cellular infiltration and the morphology of the graft appeared to be similar to the native artery (Scherner et al. 2014). The graft seemed to have a three-layered wall structure, very similar to the original carotid vessel (Wippermann et al. 2009). Smooth muscle cells in the tunica media were revealed by immunohistochemistry. In the inner surface, a layer of endothelium with a thin coating of collagen was present and the endothelization of the graft was observed at the anastomosis sites and in the centre of all implanted grafts (Wippermann et al. 2009).

The long-term use of $\mathrm{BC}$ as a vascular graft was tested in a sheep model (Malm et al. 2012). The implants were explanted after 13 months in 2 of the 6 animals introduced in this study. Four sheep showed neurological deterioration a few days after the surgery and were euthanized because of acute thrombosis. Another animal was euthanized weeks after implantation because of severe anaemia. The post mortem examination revealed that both grafts were patent without thrombosis. Ultrasound examination showed unilateral occlusion in another animal, 8 months after the primary surgery. The remaining 2 animals 
were evaluated at the planned 13 months after implantation. Three of the four grafts were patent and one had signs of dilatation. Bacterial cellulose grafts were effectively integrated with the surrounding tissue, with mild fibrotic tissue and no infection present in the implant or the nearby area. Larger controlled studies are required to prove the potential of BC in cardiology before designing clinical studies.

A combination of $\mathrm{BC}$ and a polyvinyl alcohol (PVA) composite was compared to porcine aorta (Millon and Wan 2006) and aortic heart valves (Millon and Wan 2006; Mohammadi 2011) to establish possible cardiovascular tissue replacement. Stress-strain properties in both circumferential and axial tissue directions of the composite were similar to the porcine aorta. The mechanical properties of the PVA-BC composite were comparable to heart valves. Relaxation properties measurement - an important aspect in cardiovascular applications - showed that the composite relaxed at a faster rate and to a lower residual stress. Thus, the PVA-BC nanocomposite seemed to be a promising material for cardiovascular tissue replacement (Millon and Wan 2006; Mohammadi 2011).

These vessels were successfully implanted, low immune response was shown, epithelial cell coverage and unmodified structure of BC, being applicable in small and large diameter replacement vascular grafts (Hickey and Pelling 2019). Bacterial cellulose grafts could be a good alternative in cardiovascular tissue substitute due to their haemocompatibility and mechanical resistance comparable to that of blood vessels and heart valves.

Bacterial cellulose is a potential material for small diameter vessels, but the use in animal models needs to be improved before applying it in clinical practice. The results so far seem promising, but side effects should be removed and a proper methodology should be implemented before being introduced into clinical practice. Although it has successfully mimicked the mechanical and morphological properties of heart valves, more studies are needed to create an artificial valve that simulates the properties of a native valve. Materials that combine the advantages of artificial valves and arteries with the biological counterparts are needed, and further research should be directed this way.

Nervous tissue reconstruction remains a challenge for today's veterinary medicine. The gold standard treatment of peripheral nerve damage is considered end-to-end anastomosis and transplantation (Kowalska-Ludwicka et al. 2013). Bacterial cellulose was assessed as a scaffold for peripheral nerve tissue regeneration because the fibres maintain a continuous pathway that stimulates infiltration of cells (Rajwade et al. 2015). However, less than $80 \%$ of damaged peripheral nerves were recovered; so, alternatives are being sought (Kowalska-Ludwicka et al. 2013).

Bacterial cellulose scaffolds are suitable materials for nerve cell differentiation ( $\mathrm{Zhu}$ et al. 2014) and proliferation because of the versatile surface chemistry and mechanical/ physical properties (Hickey and Pelling 2019; Roman et al. 2019). Structural and chemical modifications together with protein coating of cellulose materials can be used to increase integrin based attachment (Hickey and Pelling 2019) and cell-scaffold interactions (Kowalska-Ludwicka et al. 2013). Nerve tissue engineering is challenging because of the electrical stimulation of a group of cell types including neurons and myocytes. As a result, flexible, 3D nanostructured biomaterials are required (Rajwade et al. 2015). Bacterial cellulose scaffolds could meet these criteria because of the adjustable pore sizes and mechanical properties. Bacterial cellulose is biocompatibile and promotes neural differentiation (Hickey and Pelling 2019).

In vitro neural biocompatibility was evaluated by culturing Schwann cells (SCs) (principal cells of the peripheral nervous system) on kombucha-synthesized BC (KBC) (Zhu et al. 2014). Cultured SCs survived with a good growth on the KBC substrate, with no cytotoxicity or change in cell viability. Additional in vivo experiments were performed by implanting the tubes in site along the sciatic nerve on SD rats and 
showed no irregularities of the implant or toxicity, a slight inflammatory reaction and good biocompatibility.

Histological tissue-BC interactions and postoperative motor recovery were assessed on femoral nerve of Wistar rats (Kowalska-Ludwicka et al. 2013). Bacterial cellulose tube scaffold was compared to traditional end-to-end connection by assessing motor recovery every 30 days until explantation time. Connective tissue and a disorganization of neural structures were observed in $86.67 \%$ in the control group, compared to BC with only $35 \%$. Movement recovery increased over time in both groups. Bacterial cellulose tubes were easily isolated; they were surrounded by a thin layer of connective tissue and new small blood vessels. Despite the good histological and biocompatible results, autocannibalism was observed in the $\mathrm{BC}$ group; probably as an evidence of cumulating neurothropic factors. This behavioural disorder was not observed in the control group. Motor recovery did not differ significantly. Slight tissue response and susceptibility to neo-vascularization highlighted $\mathrm{BC}$ biocompatibility, but more studies should be done on the applicability of $\mathrm{BC}$, to avoid subsequent nervous disturbances. Although the results are promising, many studies need to be done to overcome this limitation of $\mathrm{BC}$ use in nervous tissue regeneration.

Bacterial cellulose was tested for multiple membrane applications, such as abdominal mesh (Falcão et al. 2008), urethroplasty (Huang et al. 2015) and a dura mater substitute (Angtika et al. 2018). Duraplasty is required in nearly $30 \%$ of all neurological surgeries. Several scaffolds and tissues were assessed to repair dura mater or as dural substitutes (Lima et al. 2017). Bacterial cellulose is as a biodegradable, biocompatible natural polymer, with a high mechanical strength and the potential to meet the characteristics of an ideal dura mater membrane. Is seems capable of repairing the dura mater defect in absence of cerebrospinal fluid leakage, abscess, as well as inflammatory response (Angtika et al. 2018).

Bacterial cellulose artificial dura mater was compared to the temporal fascia as a substitute in duraplasty in dogs (Xu et al. 2014). Transitory moderate symptoms were observed during the early postoperative period, which gradually faded. Fine toleration of the implant with a mild extradural fibrosis was shown macroscopically after necropsy. The fibrous tissue caused adherence of the grafts to the bone fragment. Neither macroscopic, nor microscopic examination showed implant adherence to the cortex. The graft was wrapped with connective tissue, being a suitable dural substitute.

Similar results were obtained by Lima et al. (2017) in Wistar rats when comparing BC to ePTFE: no immune reaction, infection, cerebrospinal fistulae, haemorrhages, seizures or behaviour disturbance were observed. Bacterial cellulose maintained the properties of substituted tissue and supplied suitable mechanical properties.

Another neurosurgical dural repair procedure was performed on a rabbit model with dural defects (Xu et al. 2014). The dura mater graft was derived from BC membranes. The inflammatory response and histocompatibility were assessed. The results were similar to those described in previous studies. Bacterial cellulose showed the characteristics required for artificial dura mater: mechanical properties and no cytotoxicity. The authors concluded, however, that the degradation of $\mathrm{BC}$ is still needed to be improved because of the observed foreign body reaction (Angtika et al. 2018).

Considering the results, $\mathrm{BC}$ membrane was efficient for duraplasty, but still needs further research to optimize the characteristics which support the clinical usage. Future studies should be performed to improve its effectiveness for longer periods, to obtain results that can then be applied in clinical practice.

The properties and diversity of materials used for urinary tissue reconstruction seem to be scarce and are sometimes controversial (Bodin et al. 2010; Lv et al. 2015). A multitude of autologous tissues have been used for urethral reconstruction. Colonic, buccal and 
lingual mucosa are usually used, but complications like swelling, pain, and limitations of the mouth opening have been reported (Huang et al. 2015). Tissue engineering technology may provide an alternative, and recent experimental and clinical studies have shown an encouraging performance of the BC membrane in uretroplasty (Maia et al. 2018).

Urethroplasty was performed in a rabbit model using a $3 \mathrm{D}$ porous BC scaffold implanted with lingual keratinocytes (Huang et al. 2015). Thirty New Zealand White male rabbits were divided into 3 groups and 3 scaffolds were used to repair penile urethral mucosal defect: $\mathrm{BC}, 3 \mathrm{D}$ porous $\mathrm{BC}(3 \mathrm{DpBC})$ and porous $\mathrm{BC}$ seeded with keratinocytes (3DpBCK). The first macroscopic evaluation after one month revealed broad urethral calibres with no strictures or fistulas in the $3 \mathrm{DpBCK}$ group. In the other two groups, urethral calibres were wide but some scar tissues or strictures were present. Three months after urethroplasty, wide urethral calibres were observed in group $3 \mathrm{DpBCK}$, incomplete strictures in group $3 \mathrm{DpBC}$, and complete strictures in group $\mathrm{BC}$. Histologic examination revealed no inflammatory reaction and higher tissue regeneration in group $3 \mathrm{DpBCK}$. Thus, $3 \mathrm{DpBCK}$ displayed good biocompatibility and encouraged tissue regeneration compared to $\mathrm{BC}$ and $3 \mathrm{DpBC}$.

A study performed on female Beagle dogs showed that $\mathrm{BC}$ could be used in urinary tissue reconstruction. A $2 \mathrm{~cm}$ long segment of the urethra between the bladder and the pubic symphysis was transected and removed. The animals were divided into 3 groups: one treated with BC scaffolds, one with BC-potato starch (BC/PS) and one with BC/PS seeded with muscle derived cells (BC-Vac). Histologic assessment revealed 5 to 7 intact epidermal cellular layers and organized muscle bundles in the BC-PS seeded membrane. In the $\mathrm{BC} /$ Vac group the epidermal cellular layer had only 2 to 3 layers of keratocytes and unorganized muscle fibres. In the BC group only 2 incompletely regenerated cell layers were observed with no evidence of muscle cells growing into the implant. The study demonstrated that $\mathrm{BC} / \mathrm{PS}$ may be used as scaffold with certain benefits compared to other available biologic and synthetic materials (Lv et al. 2015).

Pathology of urinary bladder needs reconstructive procedures, and the reconstructive methods often require autologous grafts ( $\mathrm{Lv}$ et al. 2015). Surgical resection of urinary bladder to treat tumours leads to the creation of a urinary reservoir using segments of the small or large intestine (Bodin et al. 2010). However, the use of these tissues presents numerous problems (Lv et al. 2015). Various biodegradable scaffolds seeded with cells were used (collagen, polyglycolic acid [PGA], polylactic-co-glycolic acid [PLGA]). Although they have suitable mechanical properties and promote tissue development, they cannot maintain a strong physical structure in vivo, when used in total bladder replacement (Bodin et al. 2010). Bladder cancer generated the need of a new material to substitute functional tissue and the physiological functions of the urinary tract (Rajwade et al. 2015). There is a considerable need for development of alternative biomaterials for urinary tissue reconstruction, given the limitations associated with conventional surgical approaches (Huang et al. 2015). The material should sustain regeneration of smooth muscle cells and achieve appropriate layer thickness that would prevent breakage when overfilled with urine (de Oliveira Barud et al. 2016).

Bacterial cellulose films were seeded with human urine-derived stem cells (USC) and tested on athymic mice (Bodin et al. 2010). Results showed that BC induced no fibrotic tissue formation and provided good growth conditions for urine derived stem cell, encouraging a favourable development of urinary conduct.

These encouraging results make $\mathrm{BC}$ and $\mathrm{BC}$ composites promising alternatives for urinary tissue reconstruction. This membrane could be used to support urethrovesical tissue engineering, since it results in minor tissue reaction and acts as a physical barrier.

Corneal injuries and ulcers require emergency keratoplasty to restore eye integrity and prevent complications (Sepúlveda et al. 2016). Ocular destructive processes (lacrimal abnormalities and traumas) determine ulcerative keratitis, which gives high morbidity 
(Macedo et al. 2010). Corneal disease is the major cause of blindness; therefore, a wide variety of materials were tested as corneal transplants (Wang et al. 2010; Ahmed et al. 2013; Sepúlveda et al. 2016). Polyvinyl alcohol is a polymer with light transparency and nutrition permeability, but it has low cell affinity. It can be mixed or grafted with starch and polyvinyl pyrrolidone (PVP) but PVA-starch and PVA-PVP composites have low tensile strength (Wang et al. 2010). The rejection rate of corneal grafts increases from $10 \%$ to $25 \%$, after 4 to 5 years and continues to increase throughout the patient's life (Sepúlveda et al. 2016).

Bacterial cellulose grafts could improve treatment of eye disease and decrease rejection rates of transplanted cornea (Rajwade et al. 2015). Its mechanical properties, water holding capacity, the ability to maintain the intraocular pressure and transparency make it a promising optical material (de Oliveira Barud et al. 2016). Bacterial cellulose is a possible candidate for contact lenses because of its transparency, light transmission, and permeability to liquids and gases (Wang et al. 2010). However, BC must be associated with other composites (PVA, polycarprolactone - PCL) to obtain full lens transparency, while maintaining its protective and regenerative properties (Coelho et al. 2019).

A BC hydrogel composite was developed and characterized for its potential use as artificial cornea biomaterial (Sepúlveda et al. 2016). Some desirable properties of artificial cornea replacement biomaterial were observed: high water content, high visible light transmittance, suitable UV absorbance, mechanical strength, and appropriate thermal properties for BC composites (Mo hite et al. 2019). In addition, appropriate materials should be used when administering locally ophthalmological antibiotics or anti-inflammatories (El-Sousi et al. 2013; Coelho et al. 2019). Unique ocular anatomy determine poor ocular drug availability, thus, drugs need to be frequently administered (El-Sousi et al. 2013). Recently, in addition to the conventional ophthalmic solutions, gels and ointments, new approaches have been attempted, such as ophthalmic films and colloidal systems which act as a support for the administration of drugs (E1-Sousi et al. 2013). The nanofibrillar structure of BC could represent an appropriate support for the incorporation (E1-Sousi et al. 2013; Ullah et al. 2016; Mohite et al. 2019) of active compounds and a controlled release system for drugs (Coelho et al. 2019).

Polycarprolactone (PCL), BC/Polycaprolactone composite (BC/PCL) and BC were tested as cornea substitutes in rabbits with induced superficial corneal ulcer (Sepúlveda et al. 2016). A number of 36 rabbits were divided into 3 groups: one group treated with $\mathrm{BC} /$ PCL, one with BC, and the control group with no membranes. Histological examination showed absence of the epithelium, fibroplasia near the implant, inflammatory infiltrate and collagen disorganization in $\mathrm{BC}$ and $\mathrm{BC} / \mathrm{PCL}$ groups. The implants protected the eye surface and remained in place. However, deficient epithelialization and a chronic inflammatory condition proved the implants inadequate as cornea substitutes in rabbits (Sepúlveda et al. 2016).

Microfibrillar BC (Bionext ${ }^{\circledR}$ ) was used to repair corneal defects after performing lamellar keratoplasty in New Zeeland rabbits (Macedo et al. 2010). The animals were evaluated clinically and histopathologically for up to 60 days. Moderate oedema, photophobia and blepharospasm were present on the second day post surgery but disappeared within a week. Histopathological examination revealed mild inflammation and a thin layer of squamous cells covering the damaged area. The implant showed good results and integration.

Thus, promising results were reported proving the efficacy of using BC composites as ophthalmic treatment. Although the $\mathrm{BC}$ membrane protected the ocular surface and remained stable, the resulting incomplete epithelialization, chronic inflammation and disorganization of collagen fibres warrants further research to find the most appropriate $\mathrm{BC}$ composite before it can be safely and efficiently used in clinical ophthalmologic practice.

Tissue engineering could bring alternative materials in the surgery of tympanic 
membrane perforation and could replace the usual myringoplasty closure (Mandour et al. 2019). Tympanic membrane perforation is a fairly common clinical problem that can become chronic, leading to hearing loss. This disease requires surgical interventions such as myringoplasty or tympanoplasty (de Oliveira Barud et al. 2016). Tissue engineering would eliminate the need for conventional surgery. Several new materials (fat graft, gel foam, and chitin) (Mandour et al. 2019) were evaluated for tympanic membrane tissue regeneration, including $\mathrm{BC}$ ( $\mathrm{Kim}$ et al. 2013). The graft materials in this operation are not suitable for day-care surgery as they require massive manipulation, meanwhile patients need a long sedation time or general anaesthesia. Bacterial cellulose could be an alternative non-toxic biocompatible material with suitable physical properties supporting cellular growth and differentiation (Mandour et al. 2019).

A BC patch was compared to spontaneous tympanic regeneration in a rat model (Kim et al. 2013). Tympanic membrane cells were seeded, proliferated and migrated in the fibrillar matrix of $\mathrm{BC}$ nanofibrilar patches. The patch promoted healing and helped in the recovery of tympanic function. The study concluded that the $\mathrm{BC}$ graft seems to be a good, simple, and safe material, and myringoplasty could be done under local anaesthesia in clinical practice. The surgery time proved shorter than usual graft materials (gel foam, fibroblastic growth factor, chitin), with better results in healing and hearing recovery (Mandour et al. 2019). However, more research is needed to have a good case record.

The use of prosthetic meshes in abdominal wall defects and hernias is a well-accepted practice leading to a reduced rate of postoperative recurrence (Silveira et al. 2016). However, the type of prosthesis best suitable for this purpose is not well established. There is a variety of materials for hernia repair; polypropylene (PP) (Zharikov et al. 2018) and polytetrafluorethylene (PTFE) (Silveira et al. 2016) are the most commonly used today. Although they have positive properties, drawbacks like chronic pain produced by fibrous tissue; inflammation of the surrounding tissues; reduced abdominal wall mobility; foreign body sensation at the implant site and infections are often noticed (Zharikov et al. 2018). The ideal mesh for abdomen reconstruction should be strong and resistant to infections, biocompatible, non-immunogenic, with minimal bio-reactivity, easily incorporated by surrounding tissues and non-adhesive. However, no current mesh meets all these requirements (Silveira et al. 2016). In this regard, it is mandatory to find and use new materials in herniology (Zharikov et al. 2018).

A BC mesh was compared to ePTFE to restore abdominal wall defects of rats (Falcão et al. 2008). A portion of the abdominal wall - including fascia, muscle and peritoneum - was excised and treated with BC or ePTFE membranes. The experimental groups were compared, and results varied widely. The ePTFE group had a significantly higher resistance to strength at implantation site interface compared to $\mathrm{BC}$ group.

Perforated BC film, compact BC film and ePTFE were compared in a similar experiment on acute defect of abdominal muscle and peritoneum in rats (Silveira et al. 2016). Meshes, peritoneum and muscles were collected postoperatively and analysed biomechanically, histologically and stereologically. Differences were observed between perforated and compact films, due to strain and elasticity; and between compact and ePTFE films. Perforated BC film is an alternative material for abdominal wall prosthesis because of superior biomechanical properties and biological compatibility. Although BC hydrogel is as an appropriate biomaterial for preventing postoperative adhesions, the gelloid properties restricted its use as abdominal mesh. Thus, $\mathrm{BC}$ composites with better properties should be developed if $\mathrm{BC}$ is to be used as an abdominal mesh (Silveira et al. 2016).

Different disease, congenital or acquired (esophageal stricture, tumours) can lead to surgical esophagus resection that needs reconstruction using scaffolds (Zhu et al. 2015a; Lua et al. 2016). Current strategies and methods involve high costs and increased risks (Lua et al. 2016). The small or large intestine and autologous stomach have been 
extensively used (Lv et al. 2015; Zhu et al. 2015a). However, their applicability is limited because of high morbidity or postsurgical complications ( $\mathrm{Lv}$ et al. 2015; Zhu et al. 2015b; Lua et al. 2016). Recently, efforts were made to develop new substitutes using several natural or synthetic materials: silicone/collagen, allogenic aorta (Zhu et al. 2015b) endoscopic balloon dilatation (Lua et al. 2016) or other tissue engineering materials ( $\mathrm{Zhu}$ et al. 2015a; Lua et al. 2016).

The ability of hydroxylated and kombucha-bacterial synthesized cellulose (HKBC) to repair esophageal defects was tested in rabbit model ( $\mathrm{Zhu}$ et al. 2015a). The defects were performed in the cervical esophagus and repaired with HKBC grafts. Survival rates, weight intake, histopathologic, haematological and radiographic assessments were noted. The survival rate was high; food intake and body weight were slowly restored. No stenosis, anastomotic discharge or obstruction of the esophagus was showed radiologically. In addition, histopathologic results showed 3 months post surgery that the substitute implant mimicked the native esophageal tissue. The authors concluded that $\mathrm{BC}$ based materials could be an encouraging graft material for esophageal replacement.

Bacterial cellulose membranes appear to be promising new covering tissues for mucosal defects because they stimulate reepithelization, decrease fibrosis and prevent stricture during the healing process. Although it seems to have a great potential for reducing the incidence of esophageal stricture, long term studies are needed for confirmation. In addition, a more extensive resection repair would be recommended for a more comprehensive clinical approach.

Bacterial cellulose was used in rat models to close an induced pharyngocutaneous fistula, a complication of total laryngectomy, and compared to primary sutures (Demir et al. 2018). The rats were grouped and treated with sutures, BC and BC membrane combined with sutures; after 7 days they were euthanized. Pharyngocutaneus fistulae development, skin wound, and inflammation were evaluated after a week. Inflammation was more intense in the $\mathrm{BC}$ sutures group than in the suture alone group. Collagen density and neovascularization did not differ significantly among the 3 groups. It was observed that the fistula decreased when $\mathrm{BC}$ was used. Bacterial cellulose could, however, be used in pharyngocutaneous fistulae treatment as it caused its decrease (Demir et al. 2018). To the best of our knowledge there is no other research on this topic and so, given the results, further studies should be done to prove the applicability of cellulose in pharyngocutaneous fistula treatment.

In summary, these results demonstrate that the mechanical and chemical properties of BC membranes can be customized by combining it with other molecules to create composites that can be adjusted to match the properties of animal soft tissues (cardiovascular, eye structures, urinary, skin). Bacterial cellulose could be used successfully in clinical veterinary practice as wound dressing and skin regeneration scaffold, due to good results so far. For a comprehensive evaluation of $\mathrm{BC}$ as a tissue substitute in cardiovascular, urinary and clinical application more studies are required.

\section{Conclusions}

Bacterial cellulose seems a promising biomaterial for tissue engineering because of its high biocompatibility and unique physiochemical properties. Thus, it has become the focus of many studies and was intensively analysed. Its properties meet the specific requirements of regeneration scaffolds: $3 \mathrm{D}$ nanofibre porous structure, biocompatibility, and resistance. Bacterial cellulose alone or as a composite (BC hydroxyapatite, $\mathrm{BC}$ biphasic calcium phosphate ceramics, BC acrylic acid, vacarine $\mathrm{BC}, \mathrm{BC}$ polyvinyl alcohol, $\mathrm{BC}$ polytetrafluoroethylene, $\mathrm{BC}$ polycaprolactone) can be used in reconstruction or healing of hard (bone, dental), cartilaginous (cartilage, meniscus) and soft tissue (skin, vascular, urinary) in a variety of animal species (dogs, pigs, sheep, rabbits and rats). 
Although many studies proved to be only experimental stages (Kowalska-Ludwicka et al. 2013; Scherner et al. 2014; Lima et al. 2017), progress has been made in the field of tissue engineering. To our knowledge, no clinical case reports have been published so far, and this would be a first step towards implementing BC in current clinical practice. The applicability in soft tissue regeneration has been extensively studied and thus $\mathrm{BC}$ and $\mathrm{BC}$ composites are used in current practice of wound treatment of humans. These promising results can be applied to current veterinary practice. Both hard and fibrocartilaginous tissue regeneration using $\mathrm{BC}$ remain at the experimental level, and further studies are needed to increase applicability and find composites that meet the properties required for each type of tissue. Although results seem promising in using $\mathrm{BC}$ as a substitute for cardiovascular, urinary and other soft tissues, more experimental studies are needed to attain $\mathrm{BC}$ composites that match the properties of native tissues. The results are promising, making $\mathrm{BC}$ a possible tissue substitute in current practice into the near future. Future studies should be aimed at in vivo and clinical studies in the usual clinical veterinary practice.

However, there are specific challenges to overcome: to harness its unique properties (3D nanofibre porous structure, adjustable mechanical properties, biocompatibility) compared to other biomaterials and to enhance its current properties. The next challenge will be finding new $\mathrm{BC}$ composite materials to produce a fully biomimetic tissue.

\section{Acknowledgements}

This project is funded by the Ministry of Research and Innovation of Romania, Projects for Financing the Excellence in CDI, Contract no. 37PFE/06.11.2018.

\section{References}

Ahmed Z, Wang Y, Ahmad A, Khan ST, Nisa M, Ahmad H, Afreen A 2013: Kefir and health: a contemporary perspective. Crit Rev Food Sci Nutr 53: 422-434

Almeida IF, Pereira T, Silva NH, Gomes FP, Silvestre AJ, Freire CS, Sousa Lobo JM, Costa PC 2014: Bacterial cellulose membranes as drug delivery systems: an in vivo skin compatibility study. Eur J Pharm Biopharm 86: 332-336

Amalraj A, Gopi S, Thomas S, Haponiuk JT 2018: Cellulose nanomaterials in biomedical, food, and nutraceutical applications: a review. Macromolecular Symposia 380: 1800115

An SJ, Lee SH, Huh JB, Jeong SI, Park JS, Gwon HJ, Kang ES, Jeong CM, Lim YM 2017: Preparation and characterization of resorbable bacterial cellulose membranes treated by electron beam irradiation for guided bone regeneration. Int J Mol Sci 18: 2236

Angtika RS, Widiyanti P, Aminatun 2018: Bacterial cellulose-chitosan-glycerol biocomposite as artificial dura mater candidates for head trauma. JBBBE 36: 7-16

Bodin A, Bharadwaj S, Wu S, Gatenholm P, Atala A, Zhang Y 2010: Tissue-engineered conduit using urinederived stem cells seeded bacterial cellulose polymer in urinary reconstruction and diversion. Biomaterials 31: $8889-8901$

Coelho F, do Vale Braido GV, Cavicchioli M, Mendes LS, Specian SS, Franchi LP, Lima Ribeiro SJ, Messaddeq Y, Scarel-Caminaga RM, O Capote, TS 2019: Toxicity of therapeutic contact lenses based on bacterial cellulose with coatings to provide transparency. Cont Lens Anterior Eye 42: 512-519

Daugela P, Pranskunas M, Juodzbalys G, Liesiene J, Baniukaitiene O, Afonso A, Sousa Gomes P 2018: Novel cellulose/hydroxyapatite scaffolds for bone tissue regeneration: In vitro and in vivo study. J Tissue Eng Regen Med 12: 1195-1208

de Oliveira Barud HG, da Silva RR, da Silva Barud H, Tercjak A, Gutierrez J, Lustri WR, de Oliveira OB, Ribeiro SJL 2016: A multipurpose natural and renewable polymer in medical applications: Bacterial cellulose. Carbohydr Polym 153: 406-420

de Souza FC, Olival-Costa H, da Silva L, Pontes PA, Lancellotti CL 2011: Bacterial cellulose as laryngeal medialization material: an experimental study. J Voice 25: 765-769

Demir B, Sari M, Binnetoglu A, Yumusakhuylu AC, Filinte D, Tekin IO, Baglam T, Batman AC 2018: Comparison of pharyngocutaneous fistula closure with and without bacterial cellulose in a rat model. Auris Nasus Larynx 45: $301-305$

El-Sousi S, Nacher A, Mura C, Catalan-Latorre A, Merino V, Merino-Sanjuan M, Diez-Sales O 2013: Hydroxypropylmethylcellulose films for the ophthalmic delivery of diclofenac sodium. J Pharm Pharmacol 65: $193-200$ 
Falcão SC, de Baros Coelho AR, Neto JE 2008: Biomechanical evaluation of microbial cellulose (Zoogloea sp.) and expanded polytetrafluoroethylene membranes as implants in repair of produced abdominal wall defects in rats. Acta Cirurgica Brasileira 23: 184-191

Feldmann E-M, Sundberg J, Bobbili B, Schwarz S, Gatenholm P, Rotter N 2013: Description of a novel approach to engineer cartilage with porous bacterial nanocellulose for reconstruction of a human auricle. J Biomater Appl 28: 626-640

Gea S, Sari RM, Piliang AF, Indrawan DP, Hutapea YA 2018: Study of bacterial cellulose as scaffold on cartilage tissue engineering. Paper presented at the AIP Conference Proceedings.

Guo W, Liu S, Zhu Y, Yu C, Lu S, Yuan M, Gao Y, Huang J, Yuan Z, Peng J, Wang A, Wang Y, Chen J, Zhang L, Sui X, Xu W, Guo Q 2015: Advances and prospects in tissue-engineered meniscal scaffolds for meniscus regeneration. Stem Cells Int 2015: 517520

Hickey RJ, Pelling AE 2019: Cellulose biomaterials for tissue engineering. Front Bioeng Biotechnol 7: 45

Huang JW, Lv XG, Li Z, Song LJ, Feng C, Xie MK, Li C, Li HB, Wang JH, Zhu WD, Chen SY, Wang HP, Xu YM 2015: Urethral reconstruction with a 3D porous bacterial cellulose scaffold seeded with lingual keratinocytes in a rabbit model. Biomed Mater 10: 055005

Huang Y, Zhu C, Yang J, Nie Y, Chen C, Sun D 2013: Recent advances in bacterial cellulose. Cellulose 21: 1-30

Iamaguti L, Brandão C, Mota L, Ranzani J, Ribeiro L, Rossetto V, Padovani C, Felisbino S 2013: Homologous articular chondrocytes implantation in osteochondral defects of dogs: technique and histopathological evaluation standardization. Arquivo Brasileiro de Medicina Veterinária e Zootecnia 65: 82-90

Iamaguti LS, Brandão CVS, Pellizzon CH, Ranzani JJT, Minto BW 2008: Análises histológica e morfométrica do uso de membrana biossintética de celulose em trocleoplastia experimental de cães. Pesquisa Veterinária Brasileira: 195-200

Kargozar S, Milan PB, Baino F, Mozafari M 2019: Nanoengineered biomaterials for bone/dental regeneration. In: Nanoengineered Biomaterials for Regenerative Medicine, Elsevier; 2019. pp. 13-38

Kim J, Kim SW, Park S, Lim KT, Seonwoo H, Kim Y, Hong BH, Choung YH, Chung JH 2013: Bacterial cellulose nanofibrillar patch as a wound healing platform of tympanic membrane perforation. Adv Healthc Mater 2: 1525-1531

Klemm D, Schumann D, Udhardt U, Marsch S 2001: Bacterial synthesized cellulose—artificial blood vessels for microsurgery. Prog Polym Sci 26: 1561-1603

Kowalska-Ludwicka K, Cala J, Grobelski B, Sygut D, Jesionek-Kupnicka D, Kolodziejczyk M, Bielecki S, Pasieka Z 2013: Modified bacterial cellulose tubes for regeneration of damaged peripheral nerves. Arch Med Sci 9: $527-534$

Kumbhar JV, Jadhav SH, Bodas DS, Barhanpurkar-Naik A, Wani MR, Paknikar KM, Rajwade JM 2017: In vitro and in vivo studies of a novel bacterial cellulose-based acellular bilayer nanocomposite scaffold for the repair of osteochondral defects. Int J Nanomedicine 12: 6437

Kwak MH, Kim JE, Go J, Koh EK, Song SH, Son HJ, Kim HS, Yun YH, Jung YJ, Hwang DY 2015: Bacterial cellulose membrane produced by Acetobacter sp. A10 for burn wound dressing applications. Carbohydr Polym 122: 387-398.

Lee SH, Lim YM, Jeong SI, An SJ, Kang SS, Jeong CM, Huh JB 2015: The effect of bacterial cellulose membrane compared with collagen membrane on guided bone regeneration. J Adv Prosthodont 7: 484-495

Lima FM, Pinto FC, Andrade-da-Costa BL, Silva JG, Campos Junior O, Aguiar JL 2017: Biocompatible bacterial cellulose membrane in dural defect repair of rat. J Mater Sci Mater Med 28: 37

Lua GW, Tang J, Liu F, Li ZS 2016: Prevention of esophageal strictures after endoscopic submucosal dissection: a promising therapy using carboxymethyl cellulose sheets. Dig Dis Sci 61: 1763-1769

Lv X, Yang J, Feng C, Li Z, Chen S, Xie M, Huang J, Li H, Wang H, Xu Y 2015: Bacterial cellulose-based biomimetic nanofibrous scaffold with muscle cells for hollow organ tissue engineering. ACS Biomater Sci Eng 2: 19-29

Macedo LR, Ribeiro AP, Conceição LFd, Galera PD, Laus JL 2010: Experimental lamellar keratoplasty in rabbits using microfibrilar cellulose membrane: clinical, morphological and immunohistochemical findings. Ciência Rural 40: 348-353

Maia G, Albuquerque AV, Martins Filho ED, Lira Neto FT, Souza VSB, Silva AAD, Lira MMM, Lima SVC 2018: Bacterial cellulose to reinforce urethrovesical anastomosis. A translational study. Acta Cir Bras 33: 673-683

Malm CJ, Risberg B, Bodin A, Backdahl H, Johansson BR, Gatenholm P, Jeppsson A 2012: Small calibre biosynthetic bacterial cellulose blood vessels: 13-months patency in a sheep model. Scand Cardiovasc J 46: 57-62

Mandour YMH, Mohammed S, Menem MOA 2019: Bacterial cellulose graft versus fat graft in closure of tympanic membrane perforation. Am J Otolaryngol 40: 168-172

Martínez Ávila H, Feldmann E-M, Pleumeekers MM, Nimeskern L, Kuo W, de Jong WC, Schwarz S, Müller R, Hendriks J, Rotter N, van Osch GJVM, Stok KS, Gatenholm P 2015: Novel bilayer bacterial nanocellulose scaffold supports neocartilage formation in vitro and in vivo. Biomaterials 44: 122-133

Martinez Avila H, Schwarz S, Feldmann EM, Mantas A, von Bomhard A, Gatenholm P, Rotter N 2014: Biocompatibility evaluation of densified bacterial nanocellulose hydrogel as an implant material for auricular cartilage regeneration. Appl Microbiol Biotechnol 98: 7423-7435 
Milcovich G, Antunes FE, Farra R, Grassi G, Grassi M, Asaro F 2017: Modulating carbohydrate-based hydrogels as viscoelastic lubricant substitute for articular cartilages. Int J Biol Macromol 102: 796-804

Millon L, Wan W 2006: The polyvinyl alcohol-bacterial cellulose system as a new nanocomposite for biomedical applications. J Biomed Mater Res Part B: Applied Biomaterials 79: 245-253

Mohamad N, Mohd Amin MC, Pandey M, Ahmad N, Rajab NF 2014: Bacterial cellulose/acrylic acid hydrogel synthesized via electron beam irradiation: accelerated burn wound healing in an animal model. Carbohydr Polym 114: 312-320

Mohammadi H 2011: Nanocomposite biomaterial mimicking aortic heart valve leaflet mechanical behaviour. Proc Inst Mech Eng H 225: 718-722

Mohite BV, Koli SH, Patil SV 2019: Bacterial cellulose-based hydrogels: synthesis, properties, and applications. In: Mondal M. (Ed.): Cellulose-Based Superabsorbent Hydrogels. Polymers and Polymeric Composites: A Reference Series. Springer, Cham, pp. 1255-1276

Neto EEM, Dolci JEL 2010: Nasal septal perforation closure with bacterial cellulose in rabbits. Braz J Otorhinolaryngol 76: 442-449

Nishiguchi A, Taguchi T 2019: Osteoclast-responsive, injectable bone of bisphosphonated-nanocellulose that regulates osteoclast/osteoblast activity for bone regeneration. Biomacromolecules 20: 1385-1393

Novaes A Jr, Novaes A, Grisi M, Soares UN, Gabarra F 1993: Gengiflex, an alkali-cellulose membrane for GTR: histologic observations. Braz Dent J 4: 65-71

Oliveira Barud HG, Barud Hda S, Cavicchioli M, do Amaral TS, de Oliveira Junior OB, Santos DM, Petersen AL, Celes F, Borges VM, de Oliveira CI, de Oliveira PF, Furtado RA, Tavares DC, Ribeiro SJ 2015: Preparation and characterization of a bacterial cellulose/silk fibroin sponge scaffold for tissue regeneration. Carbohydr Polym 128: 41-51

Petersen N, Gatenholm P 2011: Bacterial cellulose-based materials and medical devices: current state and perspectives. Appl Microbiol Biotechnol 91: 1277-1286

Picheth GF, Pirich CL, Sierakowski MR, Woehl MA, Sakakibara CN, de Souza CF, Martin AA, da Silva R, de Freitas RA 2017: Bacterial cellulose in biomedical applications: A review. Int J Biol Macromol 104: 97-106

Pigossi SC, de Oliveira GJ, Finoti LS, Nepomuceno R, Spolidorio LC, Rossa C Jr, Ribeiro SJ, Saska S, ScarelCaminaga RM 2015: Bacterial cellulose-hydroxyapatite composites with osteogenic growth peptide (OGP) or pentapeptide OGP on bone regeneration in critical-size calvarial defect model. J Biomed Mater Res A 103: 3397-3406

Qiu Y, Qiu L, Cui J, Wei Q 2016: Bacterial cellulose and bacterial cellulose-vaccarin membranes for wound healing. Mater Sci Eng C Mater Biol Appl 59: 303-309

Rajwade JM, Paknikar KM, Kumbhar JV 2015: Applications of bacterial cellulose and its composites in biomedicine. Appl Microbiol Biotechnol 99: 2491-2511

Roman M, Haring AP, Bertucio TJ 2019: The growing merits and dwindling limitations of bacterial cellulosebased tissue engineering scaffolds. Curr Opin Chem Eng 24: 98-106

Sadiasa A, Franco RA, Seo HS, Lee BT 2013: Hydroxyapatite delivery to dentine tubules using carboxymethyl cellulose dental hydrogel for treatment of dentine hypersensitivity. J Biomed Sci Eng 6: 987-995

Sajjad W, Khan T, Ul-Islam M, Khan R, Hussain Z, Khalid A, Wahid F 2019: Development of modified montmorillonite-bacterial cellulose nanocomposites as a novel substitute for burn skin and tissue regeneration. Carbohydr Polym 206: 548-556

Saska S, Barud HS, Gaspar AM, Marchetto R, Ribeiro SJ, Messaddeq Y 2011: Bacterial cellulose-hydroxyapatite nanocomposites for bone regeneration. Int J Biomater 2011: 175362

Saska S, Teixeira LN, Tambasco de Oliveira P, Minarelli Gaspar AM, Lima Ribeiro SJ, Messaddeq Y, Marchetto R 2012: Bacterial cellulose-collagen nanocomposite for bone tissue engineering. J Mater Chem 22: 22102

Scherner M, Reutter S, Klemm D, Sterner-Kock A, Guschlbauer M, Richter T, Langebartels G, Madershahian N, Wahlers T, Wippermann J 2014: In vivo application of tissue-engineered blood vessels of bacterial cellulose as small arterial substitutes: proof of concept? J Surg Res 189: 340-347

Sepúlveda RV, Valente FL, Reis ECC, Araújo FR, Eleotério RB, Queiroz PVS Borges APB 2016: Bacterial cellulose and bacterial cellulose/polycaprolactone composite as tissue substitutes in rabbits' cornea. Pesquisa Veterinária Brasileira 36: 986-992

Shahmohammadi Jebel F, Almasi H 2016: Morphological, physical, antimicrobial and release properties of ZnO nanoparticles-loaded bacterial cellulose films. Carbohydr Polym 149: 8-19

Shi Q, Li Y, Sun J, Zhang H, Chen L, Chen B, Yang H, Wang Z 2012: The osteogenesis of bacterial cellulose scaffold loaded with bone morphogenetic protein-2. Biomaterials 33: 6644-6649

Silveira RK, Coelho AR, Pinto FC, de Albuquerque AV, de Melo Filho DA, de Andrade Aguiar JL 2016: Bioprosthetic mesh of bacterial cellulose for treatment of abdominal muscle aponeurotic defect in rat model. J Mater Sci Mater Med 27: 129

Sulaeva I, Henniges U, Rosenau T, Potthast A 2015: Bacterial cellulose as a material for wound treatment: Properties and modifications. A review. Biotechnol Adv 33: 1547-1571

Suwandi J, Toes R, Nikolic T, Roep B 2015: Inducing tissue specific tolerance in autoimmune disease with tolerogenic dendritic cells. Clin Exp Rheumatol 33: S97-S103 
Tanaka ML, Vest N, Ferguson CM, Gatenholm P 2014: Comparison of biomechanical properties of native menisci and bacterial cellulose implant. Int J Polym Mater 63: 891-897

Ul-Islam M, Khan T, Khattak WA, Park JK 2012: Bacterial cellulose-MMTs nanoreinforced composite films: novel wound dressing material with antibacterial properties. Cellulose 20: 589-596

Ullah H, Wahid F, Santos HA, Khan T 2016: Advances in biomedical and pharmaceutical applications of functional bacterial cellulose-based nanocomposites. Carbohydr Polym 150: 330-352

Wang J, Gao C, Zhang Y, Wan Y 2010: Preparation and in vitro characterization of BC/PVA hydrogel composite for its potential use as artificial cornea biomaterial. Mat Sci Eng C 30: 214-218

Weber C, Reinhardt S, Eghbalzadeh K, Wacker M, Guschlbauer M, Maul A, Sterner-Kock A, Wahlers T, Wippermann J, Scherner M 2018: Patency and in vivo compatibility of bacterial nanocellulose grafts as smalldiameter vascular substitute. J Vasc Surg 68: 177S-187S

Wippermann J, Schumann D, Klemm D, Kosmehl H, Salehi-Gelani S, Wahlers T 2009: Preliminary results of small arterial substitute performed with a new cylindrical biomaterial composed of bacterial cellulose. Eur J Vasc Endovasc Surg 37: 592-596

Wu J, Yin N, Chen S, Weibel DB, Wang H 2019: Simultaneous 3D cell distribution and bioactivity enhancement of bacterial cellulose (BC) scaffold for articular cartilage tissue engineering. Cellulose 26: 2513-2528

Wu J, Zheng Y, Wen X, Lin Q, Chen X, Wu Z 2014: Silver nanoparticle/bacterial cellulose gel membranes for antibacterial wound dressing: investigation in vitro and in vivo. Biomed Mater 9: 035005

Xu C, Ma X, Chen S, Tao M, Yuan L, Jing Y 2014: Bacterial cellulose membranes used as artificial substitutes for dural defection in rabbits. Int J Mol Sci 15: 10855-10867

Yang G, Xie J, Hong F, Cao Z, Yang X 2012: Antimicrobial activity of silver nanoparticle impregnated bacterial cellulose membrane: Effect of fermentation carbon sources of bacterial cellulose. Carbohydr Polym 87: 839845

Yoshino A, Tabuchi M, Uo M, Tatsumi H, Hideshima K, Kondo S, Sekine J 2013: Applicability of bacterial cellulose as an alternative to paper points in endodontic treatment. Acta Biomater 9: 6116-6122

Zaborowska M, Bodin A, Backdahl H, Popp J, Goldstein A, Gatenholm P 2010: Microporous bacterial cellulose as a potential scaffold for bone regeneration. Acta Biomater 6: 2540-2547

Zang S, Zhuo Q, Chang X, Qiu G, Wu Z, Yang G 2014: Study of osteogenic differentiation of human adiposederived stem cells (HASCs) on bacterial cellulose. Carbohydr Polym 104: 158-165

Zharikov AN, Lubyansky VG, Gladysheva EK, Skiba EA, Budaeva VV, Semyonova EN, Zharikov AA, Sakovich GV 2018: Early morphological changes in tissues when replacing abdominal wall defects by bacterial nanocellulose in experimental trials. J Mater Sci: Mater Med 29: 95

Zhu C, Li F, Zhou X, Lin L, Zhang T 2014: Kombucha-synthesized bacterial cellulose: preparation, characterization, and biocompatibility evaluation. J Biomed Mater Res A 102: 1548-1557

Zhu C, Liu F, Qian W, Wang Y, You Q, Zhang T, Li F 2015a: Esophageal replacement by hydroxylated bacterial cellulose patch in a rabbit model. Turk J Med Sci 45: 762-770

Zhu W, Li W, He Y, Duan T 2015b: In-situ biopreparation of biocompatible bacterial cellulose/graphene oxide composites pellets. Appl Surf Sci 338: 22-26

Zimmermann KA, LeBlanc JM, Sheets KT, Fox RW, Gatenholm P 2011: Biomimetic design of a bacterial cellulose/hydroxyapatite nanocomposite for bone healing applications. Mater Sci Eng C 31: 43-49 